\title{
Expression of CD18, CD49b, CD49c and CD49e on lens anterior capsules in human cataracts
}

MRK Mathew', SM McLean², SB Murray', HGB Bennett ${ }^{1}$, LA Webb' and L Esakowitz ${ }^{1}$

\begin{abstract}
Purpose To examine the lens epithelial cells obtained from the anterior lens capsules removed during cataract surgery and detect various subclasses of the cell surface adhesion molecules known as integrins.

Methods The circular sections of anterior capsules with attached lens epithelial cells (LECs) were obtained during cataract surgery from 28 patients. The lens capsules were immunohistochemically stained.

Results CD49b CD49c, CD49e, and CD18
\end{abstract} were detected in varying degrees in specimens obtained from human cataractous lenses. The positive percentages were $33,75,33$, and $20 \%$, respectively. The most striking feature was the increasing staining profiles towards the edges of the capsules (away from the central part of the lens capsules) for $\mathrm{CD} 49 \mathrm{c}$, suggesting that the LECs showed higher immunoreactivity for this antibody. The immunoreactivity for $\mathrm{CD} 49 \mathrm{~b}$ and CD49e was weaker. This was absent for CD18 in the central part of the lens capsules.

Conclusion The positive expression of antibodies suggests that specific integrin subunits were expressed in LECs of human cataracts. These results suggest that lens epithelial cells expressing CD49b, CD49c, CD49e, and CD18 might be precursors in the process of anterior lens epithelial cell (A cell) adhesion, and hence play a role in anterior capsule opacification or in subsequent migration and a possible role in posterior capsule opacification.

Eye (2003) 17, 473-477. doi:10.1038/

sj.eye. 6700380

Keywords: anterior capsule opacification; $\mathrm{CD} 49 \mathrm{~b}, \mathrm{CD} 49 \mathrm{c}, \mathrm{CD} 49 \mathrm{e}$ and CD18; integrins; extracellular matrix proteins

\section{Introduction}

Following cataract surgery posterior capsular opacification (PCO) is the most common complication, affecting up to $50 \%$ of all adult patients after 2 years and virtually all paediatric cases. ${ }^{1,2}$ It is secondary to the migration of lens epithelial cells (LECs) from the lens equator onto the posterior lens capsule or lens epithelial metaplasia into myofibroblasts (fibrosis). ${ }^{3}$ The blocking of $\alpha_{\mathrm{v}} \beta_{3}$ integrin expression was noted to inhibit specifically LEC migration and proliferation in an animal model. ${ }^{4}$ Various authors have also suggested the role of TGF- $\beta$ in accelerating transdifferentiation and contraction of the capsular bag. ${ }^{5,6}$ These results suggest that a common feature of anterior subcapsular cataract (ASC) and PCO may be induction of an epithelial-mesenchymal transition by TGF- $\beta$. Epithelial cell proliferation, collagen deposition, basement membrane duplication, and lens fibre regeneration subsequently result in capsular opacification and visual compromise. ${ }^{7,8}$ The anterior lens epithelial cells (A cells) are the source of any form of anterior subcapsular cataract. The primary type of response of the A cells to any stimulus is to proliferate and form fibrous tissue by undergoing fibrous metaplasia, sometimes termed 'pseudofibrous metaplasia'. ${ }^{3}$

Several studies suggest that the residual LEC proliferation, differentiation, and migration onto the posterior capsule lead to PCO., $, 7,8$ Anterior capsular shrinkage and ultimate constriction (capsulorrhexis contraction syndrome or capsular phimosis) of the anterior capsulectomy opening, excessive zonular traction and its sequelae, IOL decentration, and retinal detachment can also occur. ${ }^{9-11}$

Anterior lens capsules discarded during cataract surgery contain a monolayer of epithelial cells. It has been reported that the migration of LECs in the human eye is dependent on the extracellular matrix (ECM), which could promote the adhesion of LECs. ${ }^{3-5}$
${ }^{1}$ Department of Ophthalmology Argyll and Clyde Acute Hospitals NHS Trust Paisley, Renfrewshire PA2 9PN, UK

${ }^{2}$ Department of Biological Sciences

University of Paisley

Paisley, UK

Correspondence: MRK Mathew 9 Pretoria Court Lindsayfield

East Kilbride Glasgow G75 9PE, UK

Tel.: + 44 1355-584-642 Fax: + 44 1355-584-470 E-mail: mrkmanu@ hotmail.com

Submitted in part at the Scottish Ophthalmological club meeting, Edinburgh, March 2001

Received: 25 February 2002 Accepted: 2 August 2002 
Integrins are cell adhesion molecules that have been implicated in the migration of cells to the posterior capsule of the lens. They are a family of heterodimeric membrane glycoproteins expressed on a diverse range of cell types. The glycoproteins function as the major receptors for ECM proteins and as cell-cell adhesion molecules. All integrins consist of noncovalently associated $\alpha$ and $\beta$ subunits. They bind to a variety of ECM proteins such as collagen, fibronectin, von Willebrand factor and to members of the immunoglobulin superfamily.

However, the various subtypes of lens adhesion molecules involved in anterior and posterior capsular opacification have not been identified. As the knowledge of these processes increases, the possibility of developing a number of therapeutic agents will also increase.

In this article, we report the expression of integrins in anterior capsules removed during cataract surgery. An immunohistochemical technique was used to detect the presence of integrin receptors for lens capsule components.

\section{Patients and methods}

Prior Ethics Committee approval from the Argyll and Clyde health board was obtained. The circular sections of 28 circular capsules with attached LECs were obtained during surgery from 28 patients with age-related cataract. The average age of the patients was 75 years \pm 2.49 (SD), and of the 28 patients 15 were women and 13 men. The type of cataract (six anterior subcapsular cataracts, five nuclear sclerosis, three posterior subcapsular cataracts, five cortical cataracts, and nine anterior and posterior subcapsular changes with nuclear sclerosis) prior to surgery was also noted. In the present study, no information about the intraoperative CCC size or postoperative results were available. Each capsule was immediately placed on a silane-coated glass slide.

\section{Antibodies}

All anti-integrin antibodies used were monoclonal (mAb) (Novocastra lab, Newcastle upon Tyne, UK) and are listed in Table 1 . The site of primary antibody binding was detected using a peroxidase-based avidin-biotin complex (ABC) system (Vector labs, Peterborough, UK) - in which biotinylated-immunoglobulin and peroxidase were utilized.

\section{Immunostaining}

The specimens on the glass slide were fixed in acetone for $5 \mathrm{~min}$, washed in phosphate-buffered saline (PBS), and blocked with $3 \%$ aqueous hydrogen peroxide for $10 \mathrm{~min}$ at room temperature. After rinsing, the specimens were stained with primary antibodies $\alpha_{2}, \alpha_{3}, \alpha_{5}, \beta_{1}$, and $\beta_{2}$ for $60 \mathrm{~min}$ at $37^{\circ} \mathrm{C}$.

Primary antibody was removed (with Gielson) and diluted biotinylated antibody (Vectastain ABC kit, Vector labs, Burlingame, CA, USA) was added to each slide. The specimen was incubated with Vectastain elite ABC reagent at room temperature for $30 \mathrm{~min}$. Peroxidase activity was visualized by incubating with diaminobenzidine (DAB) for $10 \mathrm{~min}$. The specimens were counterstained with haematoxylin, mounted with DPX, and observed under light microscopy. Negative control staining was performed by omission of the primary antibodies.

\section{Results}

A total of 28 human capsules obtained from cataractous lenses were analysed for immunoreactivity for CD49b, CD49c, CD49e, and CD18 antibodies. The CD49b, CD49c, CD49e, and CD18 antibodies specifically test for the integrin subunits $\alpha_{2}, \alpha_{3}, \alpha_{5}$, and $\beta_{2}$, respectively. The integrins were observed in some specimens and are portrayed in Figure 1. The individual subtypes of integrin antigens $\alpha_{2}, \alpha_{3}, \alpha_{5}$, and $\beta_{2}$ and their CD49b, CD49c, CD49e, and CD18 antibodies were analysed. The positive percentages were $2 / 6(33 \%), 6 / 8(75 \%), 3 / 9(33 \%)$ and $1 / 5(20 \%)$, respectively. There was no staining in the negative control slides. Table 2 summarizes the immunostaining results obtained from the various subtypes of integrin dimers used. CD49c $\left(\alpha_{3} \beta_{1}\right.$ dimer $)$ showed a significantly higher proportion of positive results $\left(\chi^{2}=4.72, \mathrm{df}=1, P=0.03\right)$ in comparison to CD49b, CD49e, and CD18.

The most striking staining profiles were obtained at the edges of the capsules for CD49c. The edge staining was not an artefact, as indicated by the absence of staining

Table 1 Human integrin antibodies and possible dimers

\begin{tabular}{lcllr}
\hline Antigen & Possible dimer(s) & Possible ligand(s) & Antibody (Source) & Dilution \\
\hline$\beta_{2}$ & $\alpha_{1} \beta_{2}$ & ICAM-1,2; $\mathrm{C}_{3} \mathrm{~b}_{1}$ & CD18 (Novocastra) & $1: 25$ \\
$\alpha_{2}$ & $\alpha_{2} \beta_{1}$ & Collagen I, IV; laminin & CD49b (Novocastra) & $1: 25$ \\
$\alpha_{3}$ & $\alpha_{3} \beta_{1}$ & Laminin, fibronectin, collagen I & CD49c (Novocastra) & $1: 25$ \\
$\alpha_{5}$ & $\alpha_{5} \beta_{1}$ & Fibronectin & CD49e (Novocastra) & $1: 25$ \\
\hline
\end{tabular}



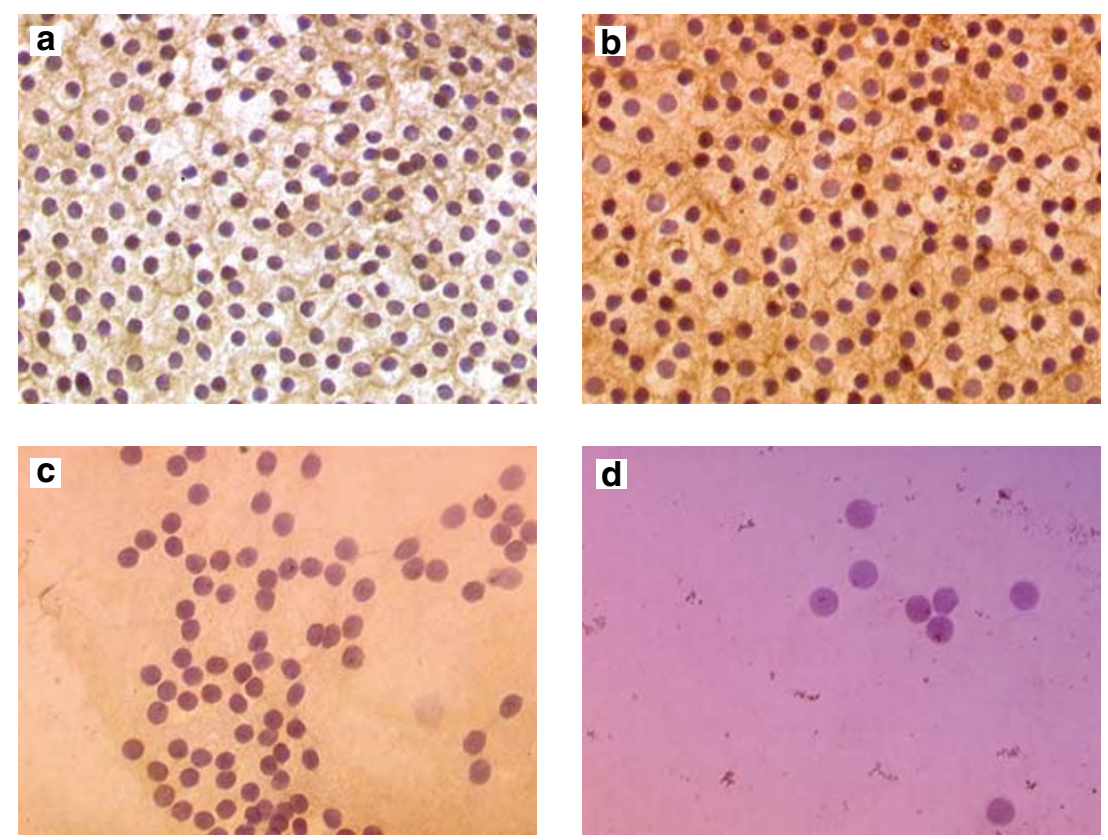

Figure 1 Expression of (a) CD49b, (b) CD49c, and (c) CD18 antibodies on the LECs of human cataract anterior capsules: (d) Negative control slides with no staining. The cell nucleus stained blue and a positive reaction produced a brown reaction (original magnification $\times 40$ ). Note the intense brown reaction with CD49c compared to CD49b and virtually no reaction with CD18.

Table 2 Individual expression of integrins in cataract LECs

\begin{tabular}{llcccr}
\hline Antigen & Antibody (source) & Cases & Positive & Negative & Positive percentage (\%) \\
\hline$\beta_{1} \alpha_{2}$ & CD49b (Novocastra) & 6 & 2 & 4 & 33 \\
$\beta_{1} \alpha_{3}$ & CD49c (Novocastra) & 8 & 6 & 2 & 75 \\
$\beta_{1} \alpha_{5}$ & CD49e (DAKO) & 9 & 3 & 6 & 33 \\
$\alpha_{2} \beta_{2}$ & CD18 (Novocastra) & 5 & 1 & 4 & 20 \\
\hline
\end{tabular}

when control immunoglobulin was substituted for anti-integrin antibodies and by the specific staining pattern (brown colour) obtained with the anti-integrin antibodies.

\section{Discussion}

Our results suggest that integrins of two different subfamilies are expressed in LECs. Integrins are transmembrane heterodimers consisting of noncovalently associated $\alpha$ and $\beta$ subunits.

Colocalization of $\alpha$ and $\beta$ subunits implies the presence of the corresponding heterodimer. ${ }^{12}$

We report here that human cataract LECs express $\alpha_{2}$, $\alpha_{3}, \alpha_{5}, \beta_{1}$ and $\beta_{2}$ integrins in specimens removed during cataract surgery. There was a higher positive expression of CD49c $\left(\alpha_{3} \beta_{1}\right.$ dimer) $(75 \%)$ in comparison to $\alpha_{2} \beta_{1}, \alpha_{5} \beta_{1}$, and $\alpha_{1} \beta_{2}$ subunits $(33,33$, and $20 \%$, respectively). In a previous report by Zhang et $\mathrm{al}^{13}$ the positive percentages of $\beta_{1}, \beta_{2}, \alpha_{2}, \alpha_{3}$, and $\alpha_{5}$ integrins were $70,65,75,70$, and
$80 \%$, respectively. In the present study, the higher positive expression of $\alpha_{3}$ and $\beta_{1}$ and a relatively poorer yield of $\alpha_{2}, \alpha_{5}$, and $\beta_{2}$ subunits may be secondary to the characteristics of the subtypes of integrins. The $\alpha_{3}$ and $\beta_{1}$ subunits are considered to be responsible for the adherence of cells to ECM components such as fibronectin, vitronectin, collagen type IV, and laminin. The $\alpha_{2}$, and $\beta_{2}$ subunits are considered to be responsible for cell-to-cell adherence. During cataract surgery, there is a breakdown of lens epithelial barrier representing altered cell surface receptor and cytoskeleton rearrangement similar to wound healing.

In 1998, Saika et $a^{14}$ reported finding prolyl 4-hydroxylase subunits, which are needed for collagen production, in human capsules with IOLs showing that LECs are able to produce collagen. Recent studies indicate type IV collagen, laminin, and fibronectin and vitronectin as important ECM proteins promoting lens epithelial cell adhesion. ${ }^{15,16}$ Integrins and other cell adhesion molecules may activate intracellular signal 
pathways, altering the response of lens epithelial cell-cell adherence and cell-ECM interaction. Residual LECs come in contact with the lens capsule or with the IOL after surgery. These cells undergo fibrous metaplasia and produce prostaglandin $\mathrm{E}_{2}$, resulting in capsular fibrosis and blood-aqueous barrier disruption. ${ }^{17,18}$

Continuous curvilinear capsulorrhexis has been postulated to affect the degree of anterior capsular opacification leading to capsule contraction syndrome. ${ }^{19}$ After CCC and IOL implantation, the area of the anterior capsule opening seems to decrease gradually for up to 3 months postoperatively. ${ }^{20-24}$ One possible explanation is the more important sphincter effect with a small capsulorrhexis. In the present study, no information about the intraoperative CCC size or postoperative results was available. Therefore, we could not correlate with the immunohistochemical staining profile at the edge of the capsulorrhexis and a subsequent role in capsule shrinkage leading to anterior capsular opacification.

The sandwich theory of $\mathrm{PCO}^{15}$ states that an IOL made of a bioactive material allows a single LEC to bond to the IOL and the posterior capsule at the same time, producing a sandwich pattern. This includes the IOL, cell monolayer, and posterior capsule. The PCO rates would hence depend on the bioactivity of IOL, ECM properties, and LEC proliferation, differentiation and migration. A sealed sandwich may prevent the epithelial in growth through this space.

In the present study, the most striking feature was an increasing staining profile obtained towards the capsulorrhexis edges of the anterior capsule. Our results suggest numerous integrin subunits being expressed prominently by proliferating cells, this being maximum in LECs towards the pre-equatorial zone. We suppose that the formation of PCO has a relationship with differentiation that includes more than the proliferation of LECs.

Cell adhesion molecules, especially integrins, play an important role in gene expression, signal transducers within the cell, as well as receptors for ECM. In our study the positive percentages of integrin expression tested were not $100 \%$, which may be the result of individual characteristics of each patient. More studies are necessary to determine the presence of unique cellular receptors on human LECs for the ECM proteins, namely fibronectin, type IV collagen, and laminin. This would therefore help us to understand the mechanisms by which these membrane proteins promote adhesion and migration of these cells. This would have clinical implications for the development of new therapeutic approaches to inhibit PCO and postoperative inflammation caused specifically by residual LECs.

\section{References}

1 McDonnell PJ, Zarbin MA, Green WR. Posterior capsule opacification in pseudophakic eyes. Ophthalmology 1983; 90: 1548-1553.

2 Moisseiev J, Bartov E, Schochat A, Blumenthal M. Long term study of the prevalence of capsular opacification following extracapsular cataract extraction. J Cataract Refract Surg 1989; 15: 531-533.

3 Apple DJ, Solomon KD, Tetz MR, Assia EL, Holland EY, Legler UF et al. Posterior capsule opacification. Surv Ophthalmol 1992; 37(2): 73-116.

4 Kim JT, Lee do H, Chung KH, Kang IC, Kim DS, Joo CK. Inhibitory effects of salmosin a disintegrin on posterior capsular opacification in vitro and in vivo. Exp Eye Res 2002; 74(5): 585-594.

5 Wormstone IM, Tamiya S, Anderson I, Duncan G. TGF-beta2-induced matrix modification and cell transdifferentiation in the human lens capsular bag. Invest Ophthalmol Vis Sci 2002; 43(7): 2301-2308.

6 Lovicu FJ, Schulz MW, Hales AM, Vincent LN, Overbeek PA, Chamberlain CG et al. TGF-beta induces morphological and molecular changes similar to human anterior subcapsular cataract. Br J Ophthalmol 2002; 86(2): 220-226.

7 Frezzotti R, Caporossi A, Mastrangelo D, Hadjistilianou T, Tosi $\mathrm{P}$, Cintorino $\mathrm{M}$ et al. Pathogenesis of posterior capsular opacification Part II: Histopathological and in vitro culture findings. J Cataract Refract Surg 1990; 16(3): 353-360.

8 Blomstedt G, Fagerholm P, Gallo J, Philipson B. After-cataract in the rabbit eye following extracapsular cataract extraction - a wound healing reaction. Acta Ophthalmol Suppl. 1987; 182(Suppl): 93-99.

9 Hansen SO, Crandall AS, Olson RJ. Progressive constriction of the anterior capsular opening following intact capsulorrhexis. J Cataract Refract Surg 1993; 19: 77-82.

10 Nishi O, Nishi K. Intraocular lens encapsulation by shrinkage of the capsulorrhexis opening. J Cataract Refract Surg 1993; 19: 544-545.

11 Nagamoto T, Hara E. Postoperative membranous proliferation from the anterior capsulotomy margin onto the intraocular lens optic. J Cataract Refract Surg 1995; 21: 208-211.

12 Korhonen M, Ylanne J, Laitinen L, Cooper HM, Quaranta V, Virtanen I. Distribution of the $\alpha_{1}-\alpha_{6}$ integrin subunits in human developing and term placenta. Lab Invest 1991; 65(3): 347-356.

13 Zhang HX, Jian J, Zhang H, Tang X, Sun HM, Yuan JQ. Detection of integrins in cataract lens epithelial cells. J Cataract Refract Surg 2000; 26: 287-291.

14 Saika S, Kawashima Y, Miyamito T et al. Immunolocalization of prolyl 4-hydroxylase subunits, $\alpha_{\text {- }}$ smooth muscle actin, and extracellular matrix components in human lens capsules with lens implants. Exp Eye Res 1998; 66: 283-294.

15 Linnola RJ, Werner L, Pandey SK, Escobar-Gomez M, Znoiko SL, Apple DJ. Adhesion of fibronectin, vitronectin, laminin, and collagen type IV to intraocular lens materials in pseudophakic human autopsy eyes. J Cataract Refract Surg 2000; 26(12): 1792-1806.

16 Olivero DK, Furcht LT. Type IV collagen, laminin, and fibronectin promote the adhesion and migration of rabbit lens epithelial cells in vitro. Invest Ophthalmol Vis Sci 1993; 34: $2825-2834$ 
17 Nishi O, Nishi K, Akaishi T, Shirasawa E. Detection of cell adhesion molecules in lens epithelial cells of human cataracts. Invest Ophthalmol Vis Sci 1997; 38: 579-585.

18 Nishi O, Nishi K. Disruption of the blood-aqueous barrier by residual lens epithelial cells after intraocular lens implantation. Ophthalmic Surg. 1992; 23: 325-329.

19 Davison JA. Capsule contraction syndrome. J Cataract Refract Surg 1993; 19: 582-589.

20 Dahlhauser KF, Wroblewski KJ, Mader TH. Anterior capsule contraction with foldable silicone intraocular lenses. J Cataract Refract Surg 1998; 24: 1216-1219.

21 Hayashi K, Hayashi H, Nakao F, Hayashi F. Reduction in the area of the anterior capsule opening after polymethylmethacrylate, silicone, and soft acrylic intraocular lens implantation. Am J Ophthalmol 1997; 123: 441-447.

22 Gonvers M, Sickenberg M, van Melle G. Change in capsulorrhexis size after implantation of three types of intraocular lenses. J Cataract Refract Surg 1997; 23: 231-238.

23 Miyake K, Ota I, Miyake S, Maekubo K. Correlation between intraocular lens hydrophilicity and anterior capsule opacification and aqueous flare. J Cataract Refract Surg 1996; 22 (Suppl): 764-769.

24 Kimura W, Yamanishi S, Kimura T, Sawada T, Ohte A. Measuring the anterior capsule opening after cataract surgery to assess capsule shrinkage. J Cataract Refract Surg 1998; 24(9): 1235-1238. 